\title{
Efeito de Exsudatos de Cultura de Células de Plantas em Juvenis de Segundo Estádio de Meloidogyne incognita*
}

\author{
Fernando S. Rocha** \& Vicente P. Campos \\ Universidade Federal de Lavras, Departamento de Fitopatologia, Cx. Postal 37, CEP 37200-000, Lavras, MG, \\ fax (035) 3829-1283, e-mail: rocha.fs@ bol.com.br
}

(Aceito para publicação em 26/02/2004)

Autor para correspondência: Fernando S. Rocha

ROCHA, F.S. \& CAMPOS, V.P. Efeito de exsudatos de cultura de células de plantas em juvenis de segundo estádio de Meloidogyne incognita. Fitopatologia Brasileira 29:294-299. 2004.

\begin{abstract}
RESUMO
Calus foram obtidos de tomateiro (Lycopersicon esculentum), cafeeiro (Coffea arabica), alfafa (Medicago sativa), orquídea (Dendrobium nobile), mostarda (Brassica rapa), batata doce (Ipomoea batatas), fumo (Nicotiana tabacum), cenoura (Daucus carota) e Crotalaria juncea em meio sólido de Murashige \& Skoog (MS) seguido do cultivo em meio líquido MS em temperatura de 25$28^{\circ} \mathrm{C}$. Após um mês, a suspensão foi passada em membrana Millipore $0,22 \mu \mathrm{m}$, obtendo-se, assim, o exsudato da cultura de células de cada planta testada. Ovos ou juvenis de segundo estádio (J2) de Meloidogyne incognita foram incubados nesses exsudatos e avaliadas as percentagens de eclosão, mobilidade e mortalidade dos J2. Com exceção dos ovos incubados em exsudato de orquídea, todos os demais

inibiram a eclosão quando comparados com a incubação em água (testemunha). Entretanto, nos exsudatos de L. esculentum, cafeeiro e C. juncea a inibição foi mais drástica, semelhante ao aldicarb, mas significativamente diferente e menor do que em soluções contendo ingredientes do meio MS (1-5). Todos os exsudatos reduziram a mobilidade e aumentaram a mortalidade, com maior intensidade em 24 h de exposição. Porém, maior redução na mobilidade ocorreu nos exsudatos de tomateiro e alfafa, enquanto maior mortalidade no exsudato de tomateiro, seguido pelo de mostarda.

Palavras-chave adicionais: calus, tomate, mostarda, alfafa, cenoura, café, Crotalaria juncea, fumo, batata doce, orquídea, nematóide das galhas, substâncias tóxicas, exsudato.
\end{abstract}

\section{ABSTRACT}

Effect of exudates of plant cell culture on second-stage juveniles of Meloidogyne incognita

Callus of Lycopersicon esculentum, Coffea arabica, Medicago sativa, Dendrobium nobile, Brassica rapa, Ipomoea batatas, Nicotiana tabacum, Daucus carota and Crotalaria juncea were obtained in Murashige \& Skoog (MS) solid medium followed by cell cultivation in MS liquid medium at temperature varying from $25-28{ }^{\circ} \mathrm{C}$. After one month, the cell suspension was passed through a $0,22 \mu \mathrm{m}$ Millipore membrane, and the resulting liquid was the cell exudate from each of the tested plants. Eggs or second-stage juveniles (J2) of Meloidogyne incognita were then incubated in these exudates and hatching, mobility and mortality percentages of the J2 were evaluated. Except for the eggs incubated in the exudate of orchid, all the exudates inhibited $\mathrm{J} 2$ hatching when compared with incubation in water (control). However, in L. esculentum, C. arabica and $C$. juncea exudates the inhibition was greatest, similar to aldicar, but significantly less and different than that found in solution of culture medium ingredients MS (1-5). All exudates reduced mobility and increased mortality of $M$. incognita $\mathrm{J} 2$, although theses were enhanced when exposed for $24 \mathrm{~h}$. The greatest reduction of mobility occurred with the exudates of tomato and $M$. sativa, while greatest mortality occurred with the exudate of L. esculentum, followed by B. rapa.

\section{INTRODUÇÃO}

Fatores bióticos e abióticos podem afetar a eclosão (Wallace, 1971; Tefft \& Bone, 1985), a mobilidade ou mesmo causar a morte de juvenis de segundo estádio (J2) de fitonematóides (Goodell \& Ferris, 1989; Campos et al., 2002). Entre eles, estão a temperatura, umidade, aeração do solo e os exsudatos radiculares.

Dentre os fatores bióticos que afetam os fitonematóides no solo estão os exsudatos de plantas (Kaplan \& Keen, 1980; Brito \& Ferraz, 1987). Os excretados pelas raízes podem conter

\footnotetext{
*Parte da Dissertação de Mestrado do primeiro autor. Universidade Federal de Lavras (2003).

***Bolsista da CAPES
}

substâncias químicas com ação nematicida ou nematostática (Gommers, 1981), podendo também conter substâncias que orientem os nematóides na direção das raízes (Bird,1959). Gommers \& Voor in'T holt (1976) verificaram que em plantas da família Compositae existem substâncias com efeito nematicida, podendo ser empregadas no controle de nematóides. Exsudatos radiculares que estimulam a eclosão podem ocorrer especialmente na soja infestada por Heterodera glycines Ichinohe, 1952 (Schmitt \& Riggs, 1991).

O exsudato excretado no solo é degradado por microorganismos (Vancura, 1988). Além disso, os microorganismos também podem afetar a exsudação alterando a permeabilidade das células das raízes e/ou afetando o seu metabolismo (Rovira, 1969). Por esse motivo, estudos mais 
Efeito de exsudatos de cultura de células de plantas...

precisos sobre exsudação radicular têm sido conduzidos sob condições controladas para, assim, evitar alterações e contaminações por substâncias produzidas por microorganismos ou por aquelas lixiviadas por folhas ou mesmo decorrentes da decomposição de matéria orgânica.

O metabolismo secundário das plantas manifesta-se em células e tecidos específicos em determinados estágios do seu crescimento, sugerindo uma íntima correlação entre crescimento e diferenciação morfológica das células. O cultivo de células, tecido ou órgãos vegetais na ausência de microorganismos constitui, então, técnica bastante promissora para se avaliar o efeito dos exsudatos sobre os nematóides. Desta forma, objetivou-se, neste trabalho, estudar o efeito de exsudatos de cultura de células de diversas plantas na eclosão, mobilidade e mortalidade de juvenis de segundo estádio de Meloidogyne incognita (Kofoid \& White, 1919) Chitwood, 1949.

\section{MATERIAL E MÉTODOS}

\section{Desinfestação das sementes, explantes e plaqueamento}

Sementes de alfafa (Medicago sativa L.), mostarda (Brassica rapa L.) e de Crotalaria juncea L. foram lavadas com água destilada e, em seguida, deixadas por $1 \mathrm{~h}$ em solução de sulfato de estreptomicina $1 \%$, contendo uma gota de Tween 80. A seguir, as sementes foram transferidas para solução de hipoclorito de sódio a $2 \%$, em câmara de fluxo laminar horizontal, permanecendo por mais $1 \mathrm{~h}$, seguida de tríplice lavagem com água destilada e esterilizada. Após a eliminação do excesso de água, foram colocadas em placas de Petri, contendo meio ágar-água $1 \%$, as quais foram vedadas e incubadas em sala de crescimento com temperatura de 25$28^{\circ} \mathrm{C}$, fotoperíodo de $16 \mathrm{~h}$ e intensidade luminosa de 35 $\mu \mathrm{mol} . \mathrm{m}^{-2} \cdot \mathrm{s}^{-1}$, suprida por lâmpadas grow-lux e branca-fria, na proporção de $1: 1$. Bons explantes para indução de calus foram obtidos das plântulas após duas semanas.

Os explantes de tomateiro (Lycopersicon esculentum Mill. cv. Kada) e de fumo (Nicotiana tabacum L.) foram obtidos de plantas jovens e saudáveis, cultivadas em casa-devegetação. Para a desinfestação dos ramos, inicialmente, fezse uma lavagem com detergente enxaguando-os com água destilada. Em seguida, sob condições assépticas, os ramos foram imersos em álcool $70 \%$ por 1 min e em hipoclorito de sódio $1 \%$ por 10 min e lavados por quatro vezes consecutivas com água destilada e esterilizada.

\section{Preparo dos calus}

Para indução dos calus, utilizou-se o meio de Murashige \& Skoog (1962), referido como MS, semi-sólido e com doses adequadas do hormônio indutor (Tabela 1), com $\mathrm{pH}$ ajustado para 5,7 $\pm 0,1$ antes de ser autoclavado a $120^{\circ} \mathrm{C}$, durante $20 \mathrm{~min}$. Na indução em tomateiro e fumo, os explantes (Tabela 1) foram cortados em fragmentos de $1 \mathrm{~cm}$ de comprimento, selecionados quanto ao aspecto de turgidez e de coloração do tecido, e colocados horizontalmente em tubos de vidro de $145 \mathrm{~mm}$ de altura por $25 \mathrm{~mm}$ de diâmetro, contendo, cada um, $15 \mathrm{ml}$ do meio MS. Em seguida, os tubos foram vedados com tampas de polipropileno e filme de pvc transparente e incubados no escuro à temperatura de $25-28^{\circ} \mathrm{C}$ até formação de calus "Friáveis". Os explantes radiculares de mostarda, alfafa e de $C$. juncea (Tabela 1) receberam incisões realizadas com a ponta da lâmina de bisturi e foram colocados na superfície do meio. Calus de cenoura (Daucus carota L.), orquídea (Dendrobium nobile Lindl.), café (Coffea arabica L.) e de batata doce [Ipomea batatas (L.) Lam.] foram obtidos a partir de plântulas micropropagadas. Para isso, os explantes foliares (Tabela 1) foram excisados em tamanhos de $1 \mathrm{~cm}^{2}$, aproximadamente, das extremidades laterais, basais e apicais. Posteriormente, foram colocados com o lado adaxial em contato com o meio e transferidos para sala de crescimento sob condições de obscuridade a $25-28{ }^{\circ} \mathrm{C}$. Os explantes de orquídea e de batata doce (Tabela 1) foram colocados para desenvolver em sala de crescimento sob condições de luz.

\section{Obtenção da cultura de células e do exsudato}

Na obtenção da cultura de células, calus "friáveis" em volume de $45 \mathrm{~cm}^{3}$ foram transferidos assepticamente para Erlenmeyers de $250 \mathrm{ml}$, contendo $100 \mathrm{ml}$ de meio líquido MS, sendo, em seguida, vedados e incubados em câmara de crescimento a $25-28{ }^{\circ} \mathrm{C}$, sob agitação constante de $100 \mathrm{rpm}$. Após um mês, em câmara de fluxo laminar, a suspensão de cultura de células crescida no meio liquido foi passada em filtro de papel Whatman $\mathrm{n}^{-} \mathbf{1}$, por duas vezes, utilizando-se bomba de sucção a vácuo e, em seguida, passada em membranas Millipore de $0,22 \mu \mathrm{m}$ de diâmetro do poro e de $4,5 \mathrm{~cm}$ de diâmetro da tela, obtendo-se assim o "exsudato de cultura de células". Esse exsudato foi estocado a $-4{ }^{\circ} \mathrm{C}$ em refrigerador até ser utilizado.

\section{Obtenção e desinfestação superficial de ovos de Meloidogyne incognita}

A partir de cultura pura de $M$. incognita, mantida em tomateiros em casa-de-vegetação, obteve-se uma suspensão de ovos pela técnica de Hussey \& Barker (1973), modificada por Boneti \& Ferraz (1981). Para promover a desinfestação superficial dos ovos utilizou-se a técnica de Coolen \& D'Herde (1972), através da qual os ovos foram separados de resíduos de raízes e de outras impurezas. Em câmara de fluxo laminar, toda a suspensão de ovos foi lavada por três vezes com água destilada e passada em peneira de $0,025 \mathrm{~mm}$, seguida da imersão dos ovos em solução de pentabiótico 300 ppm por 1 min. A seguir, os ovos foram lavados novamente com água destilada e repetida a operação de imersão no pentabiótico por quatro vezes. Após esse procedimento os ovos estavam desinfetados e prontos para a montagem do ensaio de eclosão.

\section{Obtenção de juvenis do segundo estádio (J2) de $M$. incognita}

Raízes de tomateiros cv. Kada cultivados em casa de vegetação e infetadas com $M$. incognita foram lavadas cuidadosamente e cortadas em pedaços de um centímetro. A seguir, foram batidas em liqüidificador por $20 \mathrm{~s}$ em solução 
F.S. Rocha \& V.P. Campos

TABELA 1 - Doses dos hormônios reguladores de crescimento adicionados ao meio MS para obtenção de calus de diferentes espécies vegetais, além do tipo de explante, fotoperíodo e tempo para formação de calus friável

\begin{tabular}{|c|c|c|c|c|}
\hline Família botânica / Espécie vegetal & $\begin{array}{c}\text { Dose do regulador de } \\
\text { crescimento }\end{array}$ & $\begin{array}{c}\text { Tipo de } \\
\text { explante }\end{array}$ & $\begin{array}{l}\text { Fotoperíodo } \\
\text { (Luz/Escuro) }\end{array}$ & $\begin{array}{c}\text { Tempo } \\
\text { (dias) }\end{array}$ \\
\hline Fabaceae / Medicago sativa L. & $1,0 \mathrm{mg} / 1 \mathrm{de} 2,4-\mathrm{D}$ & Raiz & Escuro & 30 \\
\hline Convolvulaceae / Ipomoea batatas (L.) Lam. & $2,0 \mathrm{mg} / 1 \mathrm{de}$ BAP & Folha & Luz & 35 \\
\hline Rubiaceae / Coffea arabica $\mathrm{L}$. & $\begin{array}{l}1,0 \mathrm{mg} / 1 \text { de } 2,4-\mathrm{D} \\
2,0 \mathrm{mg} / 1 \text { de cinetina }\end{array}$ & Folha & Escuro & 180 \\
\hline Umbelliferae / Daucus carota L. & $\begin{array}{l}0,3 \mathrm{mg} / 1 \text { de } 2,4-\mathrm{D} \\
0,1 \mathrm{mg} / 1 \text { de cinetina }\end{array}$ & Folha & Escuro & 35 \\
\hline Fabaceae / Crotalaria juncea L. & $1,0 \mathrm{mg} / 1 \mathrm{de} 2,4-\mathrm{D}$ & Raiz & Escuro & 30 \\
\hline Solanaceae / Nicotiana tabacum L. & $\begin{array}{l}0,3 \mathrm{mg} / 1 \text { de } 2,4-\mathrm{D} \\
0,1 \mathrm{mg} / 1 \text { de cinetina }\end{array}$ & Caule & Escuro & 30 \\
\hline Cruciferae / Brassica rapa $\mathrm{L}$. & $1,0 \mathrm{mg} / 1$ de $2,4-\mathrm{D}$ & Raiz & Escuro & 30 \\
\hline Orchidaceae / Dendrobium nobile Lindl. & $2,0 \mathrm{mg} / 1 \mathrm{de}$ BAP & Gema & Luz & 33 \\
\hline Solanaceae / Lycopersicon esculentum Mill. & $\begin{array}{l}2,0 \mathrm{mg} / 1 \mathrm{de} \text { ANA } \\
1,0 \mathrm{mg} / 1 \mathrm{de} \text { BAP }\end{array}$ & Caule & escuro & 40 \\
\hline
\end{tabular}

* 2,4-D: ácido 2,4-diclorofenoxiacético; BAP: 6-benzilaminopurina; ANA: ácido $\alpha$-naftalenoacético

de hipoclorito de sódio a 0,5\%, seguindo-se a técnica de Hussey \& Barker (1973), modificada por Boneti \& Ferraz (1981). Em seguida, colocaram-se aproximadamente $3 \mathrm{~g}$ de caulim por tubo, realizando-se a limpeza dos ovos pela técnica de Coolen \& D'Herde (1972). Os ovos retidos na peneira de $0,025 \mathrm{~mm}$ foram recolhidos em béquer de $200 \mathrm{ml}$, utilizandose pisseta contendo água destilada. Em câmara de fluxo laminar, toda a suspensão foi passada em peneira esterilizada de $0,025 \mathrm{~mm}$ e os ovos foram lavados por quatro vezes em água destilada e então colocados em béquer de vidro esterilizado. Para a obtenção dos J2, utilizou-se uma câmara de eclosão formada com tela e papel de espessura fina, colocados num funil de vidro esterilizado.

\section{Montagem e avaliação dos ensaios}

No ensaio de eclosão, em câmara de fluxo laminar, $300 \mu \mathrm{l}$ da solução de exsudato de cultura de células diluído 1:1 (exsudato: água), meio MS, meio MS com hormônio indutor de calus, aldicarb $50 \mathrm{ppm}$ ou água destilada e esterilizada foram colocados em cada célula da placa Elisa. A seguir, a suspensão de ovos desinfetada foi colocada em vidro relógio. Em microscópio de objetiva invertida separaram-se, com o auxilio de um estilete, vinte ovos com juvenil formado em seu interior, os quais foram selecionados pelo tamanho e pelo estádio de desenvolvimento do juvenil. Após a seleção e separação, os ovos foram removidos com o auxilio de uma pipeta automática de $20 \mu \mathrm{l}$ e transferidos para cada célula da placa Elisa. Em seguida, a placa foi vedada com filme de pvc transparente e incubada em estufa (B.O.D.) em temperatura de $28^{\circ} \mathrm{C}$ por sete dias. Ao final desse tempo, os $\mathrm{J} 2$ eclodidos foram contados em microscópio de objetiva invertida no aumento de $32 \mathrm{X}$.

Utilizou-se o delineamento em blocos casualizados, com oito repetições. Cada célula da placa Elisa constituiu-se numa unidade experimental. Os dados foram transformados em $\sqrt{x+0.5}$ para a realização da análise de variância. Na comparação entre as médias utilizou-se o teste de Scott \& Knott (1974) a 5\% de probabilidade.

No ensaio de mobilidade, foram colocados $200 \mu \mathrm{lde}$ solução de exsudato de cultura de células em cada célula de placa Elisa estéril. A seguir, foram pipetados $100 \mu 1$ de suspensão de J2 previamente calibrada, com $200 \mathrm{~J} 2$, obtidos como descrito anteriormente, e transferidos para cada célula da placa Elisa contendo o exsudato. Foram utilizados nos ensaios apenas os $\mathrm{J} 2$ obtidos no terceiro dia. Após esse procedimento a placa foi vedada com filme de pvc transparente e incubada a $26^{\circ} \mathrm{C}$ em B.O.D. por 12 ou 24 h. Passado esse tempo, os J2 foram removidos de cada célula da placa Elisa com o auxilio de uma pipeta automática de $1 \mathrm{ml}$ e transferidos para placas de Petri de plástico de 4,5 $\mathrm{cm}$ de diâmetro para leitura em microscópio do número de J2 móveis. A seguir, os J2 foram novamente transferidos para peneira formada de tela de 11 $\mu \mathrm{m}$, enxaguados com água destilada, substituindo assim o exsudato, e recolhidos com jatos de água com pipeta automática de $10 \mathrm{ml}$ para placa de Petri. Nessa condição foram incubados a $26^{\circ} \mathrm{C}$ por $12 \mathrm{~h}$. Após esse tempo de exposição, foi avaliado o número de $\mathrm{J} 2$ aparentemente inativos em microscópio de objetiva invertida. Os J2 foram considerados inativos quando não se movimentavam ou apresentavam o corpo com aspecto retilíneo ou retorcido. Espécimens que permaneceram inativos após $12 \mathrm{~h}$ em água, foram classificados como mortos. Nesse ensaio, utilizou-se o delineamento inteiramente casualizado, com seis repetições e transformação dos dados e teste estatístico semelhantes aos citados anteriormente.

\section{RESULTADOS E DISCUSSÃO}

Eclosão de juvenis do segundo estádio (J2) de M. incognita Com exceção dos ovos incubados em exsudato de 
Efeito de exsudatos de cultura de células de plantas...

orquídea, todos os demais reduziram $(\mathrm{P} \leq 0,05)$ a eclosão de J2 se comparada com a incubação em água (Figura 1). Entretanto, nos exsudatos de tomateiro, cafeeiro e $C$. juncea a inibição foi mais $(\mathrm{P} \leq 0,05)$ drástica e semelhante $(\mathrm{P} \leq 0,05)$ ao aldicarb (Figura 1), e significativamente diferente e menor $(\mathrm{P} \leq 0,05)$ do que em soluções contendo ingredientes do meio MS (1 a 5) (Figura 1).

Como os ovos, utilizados nesse ensaio, já continham o juvenil formado internamente, o efeito das substâncias contidas na composição do meio MS e nos exsudatos celulares pode ter afetado a acetilcolinesterase levando o $\mathrm{J} 2$ a diminuir seus movimentos (Nelmes, 1970) ou retardando o processo de degradação da camada lipídica e da plasticidade da casca do ovo, que são eventos necessários para a eclosão do J2 (Doncaster \& Shepherd, 1967). Esses dois processos de atuação de substâncias retardando a eclosão, podem, talvez, embasar a hipótese de que as plantas de alfafa, batata doce, cenoura, fumo e mostarda possam produzir exsudatos tóxicos em pequenas quantidades, in vitro; porém, o local de atuação é diferente das substâncias contidas nos meios MS (1 a 5). Entretanto, a produção de substâncias retardadoras da eclosão foi significativamente maior em culturas de células de tomateiro, cafeeiro e C. juncea. Baumann \& Rohrig (1989), analisando exsudato de suspensão de cultura de células de cafeeiro cultivado no escuro, encontraram níveis consideráveis de cafeína e ácido clorogênico no meio. Mahajan et al. (1985) encontraram redução na eclosão de $\mathrm{J} 2$ de $M$. incognita pelos compostos fenólicos, acido clorogênico e caféico.

Estudos com exsudatos de culturas de células com efeito antagônico a fitonematóides inexistem na literatura; porém, pesquisas têm sido feitas com outros organismos. Balota et al. (1995), trabalhando com bactérias diazotróficas e fungos micorrízicos arbusculares, usaram exsudato produzido in vitro por plântula de mandioca micropropagada, no cultivo de Azospirillum lipoferum (Beijerinck, 1925) Tarrand et al, 1979, Klebsiela sp. e Gigaspora gigantea (Nicolson \& Gendemann, 1968) Gendemann \& Trappe, 1874, e constataram maior crescimento desses organismos na presença desses exsudatos.

\section{Mobilidade}

Todos os exsudatos reduziram $(\mathrm{P} \leq 0,05)$ a mobilidade dos $\mathbf{J} 2$ comparado com a incubação em água (testemunha) e em ingredientes do meio em qualquer período de exposição testado (Figura 2). Contudo, a exposição dos J2 por $24 \mathrm{~h}$ revelou toxicidade diferente desses exsudatos, além de reduzir ainda mais a mobilidade em qualquer exsudato testado. Porém, maior redução na mobilidade de $\mathrm{J} 2$ ocorreu em exsudato de tomateiro e alfafa, seguidos de cafeeiro, mostarda e cenoura ao nível ou maior do que em aldicarb (Figura 2).

Como, nesse ensaio, o J2 estava livre, o efeito único das substâncias exsudadas pelas células ou oriundas da composição do meio MS (1 a 5) pode ter sido na acetilcolinesterase controladora do movimento do J2 (Nelmes, 1970). Dessa forma, os ingredientes do meio não afetaram tal enzima (Figura 2). Contudo, substâncias diversas e em níveis tóxicos ao J2 diferentes foram produzidas pelas células das plantas testadas (Figura 2). Zhao et al. (2000) verificaram que os J2 de $M$. incognita, quando incubados por $30 \mathrm{~min}$ em exsudato de células da borda de alfafa, feijão (Phaseoalum vulgaris L.), ervilha (Pisum sativum L.) e milho (Zea mays L.), perderam a motilidade e ficaram inativos. Segundo os autores, esses exsudatos reduziram em mais de $80 \%$ a motilidade desse nematóide. Jatala \& Russel (1972), estudando a natureza da resistência de batata doce a Meloidogyne javanica (Treub, 1885) Chitwood, 1949, verificaram que a sua resistência era

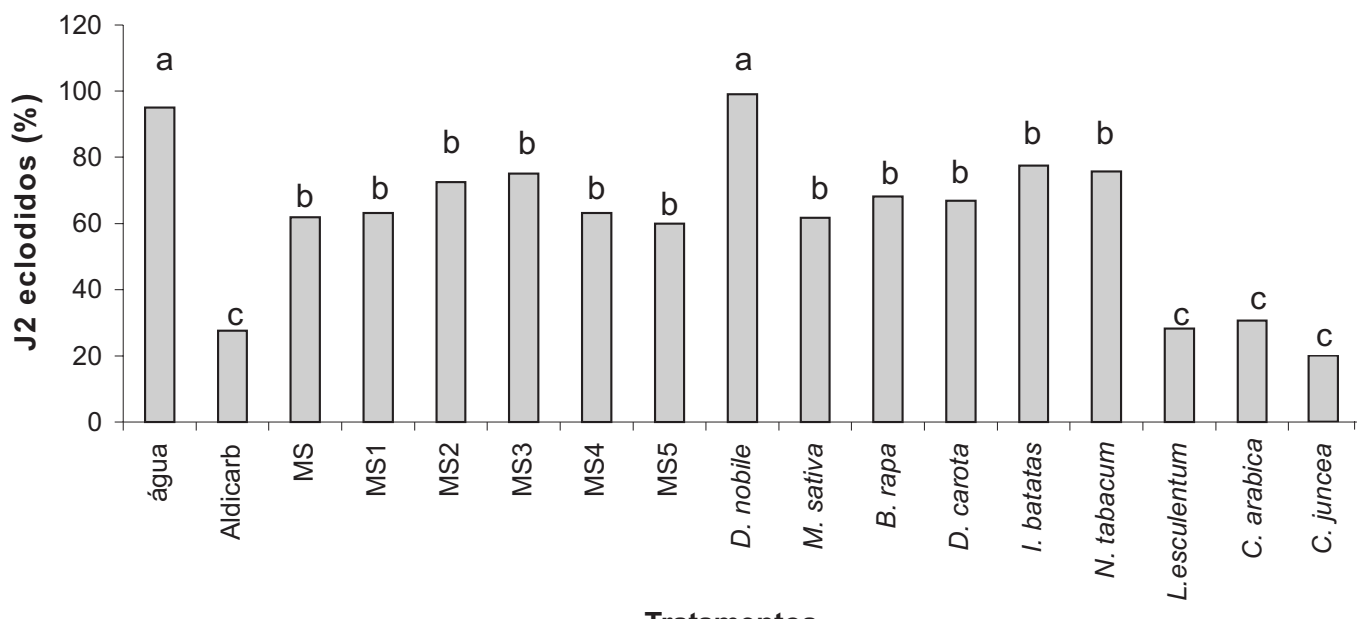

Tratamentos

FIG. 1 - Porcentagem de juvenis do segundo estádio (J2) de Meloidogyne incognita eclodidos após incubação por sete dias a $28{ }^{\circ} \mathrm{C}$ em exsudatos de cultura de células de orquídea (Dendrobium nobile), alfafa (Medicago sativa), mostarda (Brassica rapa), cenoura (Daucus carota), batata doce (Ipomea batatas), fumo (Nicotiana tabacum), tomateiro (Lycopersicon esculentum), cafeeiro (Coffea arabica), Crotalaria juncea, e nas testemunhas (água estéril, aldicarb 50 ppm, meio MS, MS1: meio MS mais 1 mg/l de 2,4-D-ácido 2,4-diclorofenoxiacético, MS2: meio MS mais $2 \mathrm{mg} / \mathrm{l}$ de BAP-6-benzilaminopurina, MS3P: meio MS mais 0,3 mg/l de 2,4-D e 0,1 mg/l de cinetina, MS4: meio MS mais $2 \mathrm{mg} / \mathrm{l}$ de ANA-ácido $\alpha$-naftalenoacético e $1 \mathrm{mg} / \mathrm{l}$ de BAP, MS5: meio MS mais $1 \mathrm{mg} / \mathrm{l}$ de 2,4-D e $2 \mathrm{mg} / \mathrm{l}$ de cinetina. Barras seguidas pela mesma letra não diferem significativamente entre si pelo teste de Scott \& Knott (1974) a 5\% de probabilidade. 


\section{F.S. Rocha \& V.P. Campos}

devida a uma combinação de fatores, dentre eles a produção de exsudatos radiculares repelentes. Em outro estudo, Diez \& Dusenbery (1989) observaram que exsudato radicular de tomate extraído com solvente orgânico revelou atividade repelente a $M$. incognita.

\section{Mortalidade}

Todos os exsudatos causaram mortalidade $(\mathrm{P} \leq 0,05)$ comparados com a incubação do J2 em água (testemunha) e em ingredientes do meio MS (1 a 5), com maior intensidade quando a exposição foi de $24 \mathrm{~h}$, porém, bem inferior $(\mathrm{P} \leq$ 0,05 ) daquela em aldicarb (Figura 3). No entanto, a maior mortalidade $(\mathrm{P} \leq 0,05)$ ocorreu quando os $\mathrm{J} 2$ foram colocados no exsudato de tomate, seguido pelo de mostarda em relação a água (testemunha).

A perda da mobilidade de quase $100 \%$ dos $\mathrm{J} 2 \mathrm{em}$

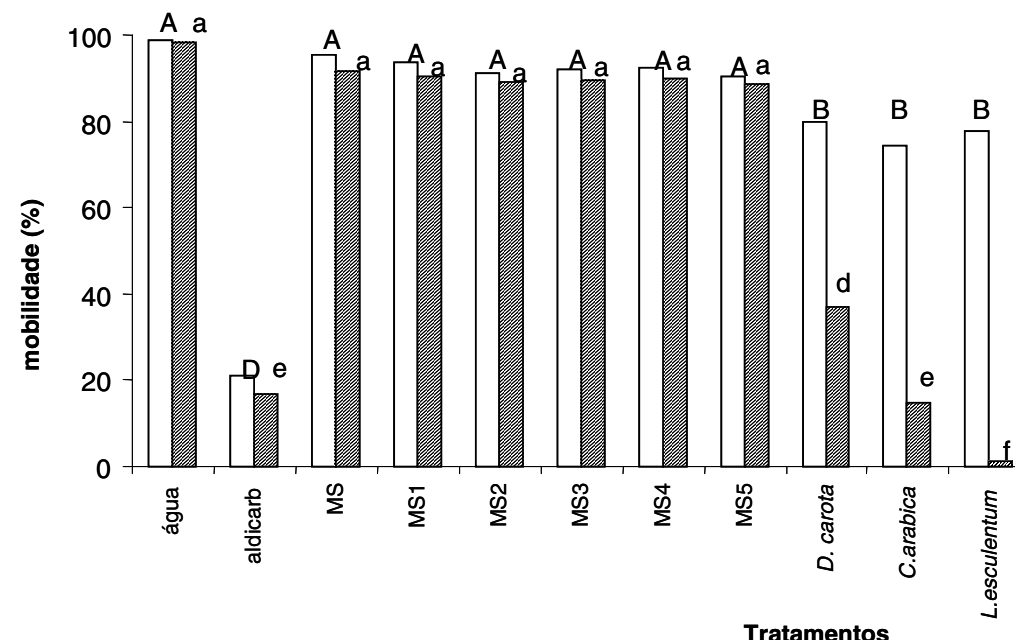

FIG. 2 - Efeito dos exsudatos de cultura de células de tomateiro (Lycopersicon esculentum), cafeeiro (Coffea arabica), alfafa (Medicago sativa), orquídea (Dendrobium nobile), mostarda (Brassica rapa), batata doce (Ipomea batatas), fumo (Nicotiana tabacum), cenoura (Daucus carota), Crotalaria juncea e nas testemunhas (água estéril, aldicarb 50 ppm, meio MS, MS1: meio MS mais 1 mg/l de 2,4-D-ácido 2,4diclorofenoxiacético, MS2: meio MS mais $2 \mathrm{mg} / \mathrm{l}$ de BAP-6-benzilaminopurina, MS3: meio MS mais 0,3 mg/l de 2,4-D e 0,1 mg/l de cinetina, MS4: meio MS mais $2 \mathrm{mg} / \mathrm{l}$ de ANA-ácido $\alpha$-naftalenoacético e $1 \mathrm{mg} / \mathrm{l}$ de BAP, MS5: meio MS mais $1 \mathrm{mg} / \mathrm{l}$ de 2,4-D e 2 mg/l de cinetina na mobilidade de juvenis do segundo estádio (J2) de Meloidogyne incognita após 12 ou 24 h de incubação. Barras seguidas pela mesma letra maiúscula ou minúscula, nas colunas, não diferem significativamente entre si pelo teste de Scott \& Knott (1974) a 5\% de probabilidade.

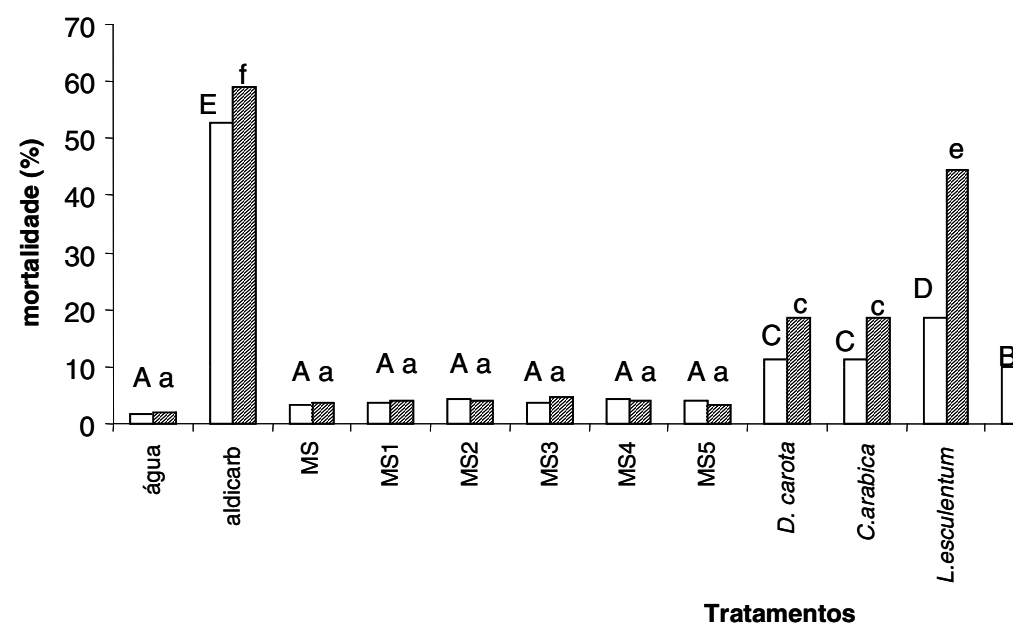

FIG. 3 -Efeito dos exsudatos de cultura de células de tomateiro (Lycopersicon esculentum), cafeeiro (Coffea arabica), alfafa (Medicago sativa), orquídea (Dendrobium nobile), mostarda (Brassica rapa), batata doce (Ipomea batatas), fumo (Nicotiana tabacum), cenoura (Daucus carota), Crotalaria juncea e nas testemunhas (água estéril, aldicarb 50 ppm, meio MS, MS1: meio MS mais 1 mg/l de 2,4-D-ácido 2,4diclorofenoxiacético, MS2: meio MS mais 2 mg/l de BAP-6-benzilaminopurina, MS3: meio MS mais 0,3 mg/l de 2,4-D e 0,1 mg/l de cinetina, MS4: meio MS mais $2 \mathrm{mg} / \mathrm{l}$ de ANA-ácido $\alpha$-naftalenoacético e $1 \mathrm{mg} / \mathrm{l}$ de BAP, MS5: meio MS mais $1 \mathrm{mg} / \mathrm{l}$ de 2,4-D e 2 mg/l de cinetina na mortalidade de juvenis do segundo estádio (J2) de Meloidogyne incognita após 12 ou 24 h de incubação. Barras seguidas pela mesma letra maiúscula ou minúscula, nas colunas, não diferem significativamente entre si pelo teste de Scott \& Knott (1974) a 5\% de probabilidade. 
Efeito de exsudatos de cultura de células de plantas...

exsudatos de tomate e de alfafa em 24 h de exposição não resultou em valores tão altos de mortalidade ficando em 45 e $15 \%$, respectivamente. Considerando os ensaios de eclosão, mobilidade e mortalidade realizados, exsudato de tomate foi o mais tóxico a J2 de M. incognita. Awad et al. (1997) usando exsudato radicular de tomate, cebola (Allium cepae L.) e alho (Allium sativum L.) obtidos aos 15 dias de idade encontraram alta mortalidade de $\mathrm{J} 2$ de $M$. incognita e relacionaram tal atividade com a presença de compostos fenólicos nos tecidos desses hospedeiros aos 45 dias de idade.

A inserção dos estudos com exsudatos "in vitro" na fitonematologia deve avançar com a pesquisa de outras plantas e comparando a produção in vitro com exsudato oriundo dos tecidos radiculares da planta. Além disto, a facilidade na obtenção e a pureza dos exsudatos de células, também comentados por Balota et al. (1995) possibilitam estudos de purificação e de caracterização das moléculas tóxicas a fitonematóides. Em contraste com os lixiviados e difusatos, estudos de purificação de princípios tóxicos se tornam difíceis, pois substâncias liberadas pelas plantas podem se transformar noutras pelas reações químicas na rizosfera e pela degradação por microorganismos tornando-se difícil correlacioná-las com aquelas originais do exsudato da planta. No futuro, talvez, a geração de produtos nematicidas biológicos poderá ser possível a partir de suspensão de cultura de células.

\section{REFERÊNCIAS BIBLIOGRÁFICAS}

AWAD, N.G.H., EI-TOONY, A.M.E., TADROUS, M.F.I. \& KHALIL, M.A.I. Efficacy of root exudates and extracts of tomato, garlic and onoin on Fusarium oxysporum f. sp. lycopersici, F. oxysporum f. sp. cepae and Meloidogyne incognita. Arabian Universities Journal of Agricultural Sciences 5:105-120. 1997.

BALOTA, E.L., LOPES, E.S., HUNGRIA, M. \& DOBEREINER, J. Interações e efeito fisiológico de bactérias diazotrópicas e fungos micorrízicos arbusculares na mandioca. Pesquisa Agropecuária Brasileira 30:1335-1345. 1995.

BAUMANN, T.W. \& ROHRIG, L. Formation and intracellular accumulation of caffeine and chlorogenic acid in suspension cultures of Coffea arabica. Phytochemistry 28:2667-2669. 1989.

BIRD, A.F. The attractiveness of roots to the plant parasitic nematodes Meloidogyne javanica and M. hapla. Nematologica 4:322-335. 1959.

BONETI, J.I.S. \& FERRAZ, S. Modificação do método de Hussey e Barker para extração de ovos de Meloidogyne exigua de cafeeiro. Fitopatologia Brasileira 6:553. 1981.

BRITO, J.A. de \& FERRAZ, S. Antagonismo de Brachiaria decumbens e Panicum maximum cv. Guiné a Meloidogyne javanica. Nematologia Brasileira 11:270-285. 1987.

CAMPOS, H.D., CAMPOS, V.P., RIBEIRO, L.O. \& CAMPOS, J.R. Efeito de exsudato radicular de Brachiaria decumbens sobre a eclosão e mobilidade de juvenis do segundo estádio de Meloidogyne javanica. Fitopatologia Brasileira 27:185-186. 2002 (Resumo).

COOLEN, W.A. \& D'HERDE, C.J. A method for the quantitative extraction of nematodes from plant tissue culture. Ghent: State Agriculture Research Centre 1972.

DIEZ, J.A. \& DUSENBERY, D.B. Repellent of root-knot nematodes from exudate of host roots. Journal of Chemical Ecology 15:24452455. 1989.

DONCASTER, C.C. \& SHEPHERD, A.M. The behaviour of secondstage Heterodera rostochiensis larvae leading to their emergence from the egg. Nematologica 13:476-478. 1967.

GOMMERS, F.J. \& VOOR IN'T HOLT, D.J.M. Chemotaxonomy of compositae related to their host suitability for Pratylenchus penetrans. Netherland Journal of Plant Pathology 82:1-8. 1976.

GOMMERS, F.J. Biochemical interactions between nematodes and plants and their relevance to control. Helminthological Abstracts 50: 9-21. 1981.

GOODELL, P.B. \& FERRIS, H. Influence of envirommental factors on the hatch and survival of Meloidogyne incognita. Journal of Nematology 21:328-334. 1989.

HUSSEY, R.S. \& BARKER, K.R. A comparison of methods for colecting inocula of Meloidogyne spp including a new technique. Plant Disease Repórter 57:1025-1028. 1973.

JATALA, R. \& RUSSEL, C.C. Nature of sweet potato resistance to Meloidogyne incognita and the effects of temperature on parasitism. Journal of Nematology 4:1-7. 1972.

KAPLAN, D.T. \& KEEN, N.T. Mechanisms conferring plant incompatibility to nematodes. Revue de Nématologie 3:123-134. 1980.

MAHAJAN, R., SINGH, P. \& BAJAJ, K.L. Nematicidal activity of some phenolic compounds against Meloidogyne incognita. Revue de Nématologie 8:161-164. 1985.

MURASHIGE, T. \& SKOOG, F. A revised medium for rapid growth and bioassays with tobacco tissue cultures. Physiology Plantarum 15:473-497. 1962.

NELMES, A.J. Behavioral responses of Heterodera rostochiensis larvae to aldicarb and its sulfoxide and sulfone. Journal of Nematology 2: 223-227. 1970.

ROVIRA, A.D. Plant root exudates. The Botanical Review 35:35-57. 1969.

SCHMITT, D.P. \& RIGGS, R.D. Influence of selected plant species on hatching of eggs and development of juveniles of Heterodera glycines. Journal of Nematology 23:1-6. 1991.

SCOTT, A.J. \& KNOTT, M. Cluster analysis method for grouping means in the analysis of variance. Biometrics 30:507-512.1974.

TEFFT, P.M. \& BONE, L.W. Plant-induced hatching of eggs of the soybean cyst nematode Heterodera glycines. Journal of Nematology 17:275-279.1985.

VANCURA, V. Microorganisms, their mutual relations and functions in the rhizosphere. In: Vancura, V. \& Kunc, F. (Eds.) Soil Microbial Associations. Amsterdam: Elservier, 1988. pp.191-266.

WALLACE, H.R. The influence of temperature on embryonic development and hatch of Meloidogyne javanica. Nematologica 171:179-186. 1971.

ZHAO, X., SCHMITT, M. \& HAWES, C.M. Species-dependent effects of border cell and root tip exudates on nematodes behavior. Phytopathology 90:1239-1245. 2000. 